\title{
CHANGING PERSONAL RULES
}

\author{
David P. Himle \\ University of Michigan
}

ABSTRACT: This article examines the characteristics and types of personal rules and traditions, and illustrates how they may be maladaptive to the individual. Suggestions are given to improve methods of assessment and intervention strategies for the development of more adequate rules, by a combination of cognitive and operant approaches, which take into account both environmental consequences and feedback.

One of the goals of cognitive therapy is to assist individuals in modifying various cognitive errors and beliefs which are maladaptive and result in dysfunctional emotions and behavior. One of these cognitive events is the personal rule. The relationship between personal rules and behavior is self-evident and has been addressed by several authors in the cognitive therapy literature (Beck \& Emery, 1985; Zettle \& Hayes, 1982). In general, rules are usually assessed and treated in the same manner as irrational beliefs or cognitive errors. Yet, rules have special characteristics which require a somewhat unique assessment and treatment approach. The purpose of this article is to present additional information to develop a more systematic understanding of the broad range of rule development and usage, to suggest improvements in rule assessment and modification, and to examine both the cognitive and operant aspects of this process.

\section{A COMMON EXAMPLE}

The influence of rules and traditions is so pervasive that it is difficult to conceive of a behavior which is not controlled, or the target of

Address reprint requests to David P. Himle, Ph.D., Associate Professor of Social Work, University of Michigan, Ann Arbor, MI 48109. The author is grateful to Joseph A. Himle for his constructive editorial comments. 
control, by a rule derived from individuals or families. It is also difficult to assess the variety of rules which guide individual behavior because they are seldom examined in detail and because the response to them is so habitual.

As an example, let us consider a behavior which is perceived as enjoyable by many people, namely, the giving or receiving of compliments. Even though the acts of giving or receiving compliments may be perceived as rather simple behaviors, a sampling of the rules governing them will illustrate the complexity, range, and precision of rules and their power to alter the frequency of behavior.

Clients frequently report a number of constraints (usually in the form of rules) which hinder giving of compliments, such as: "I don't give compliments, the other person will feel that he or she has to return them;" or, "I don't give compliments, they might be misinterpreted;" or, "In my family we never give compliments;" or, "I don't give my friends compliments, they should know how I feel."

How one receives compliments is also the subject of rules, such as: "I always return one compliment with another;" or, "If you express appreciation for a compliment people will think you are vain."

Because of such constraints, some therapeutic procedures may be difficult to implement. For example, attempts to increase marital satisfaction through positive exchanges, such as used in behavioral marital therapy, may be impossible because of the interference of personal rules. If such exchanges include compliments, they may not be possible until rules, which prohibit or discount their use, are amended or discarded. Therefore, the assessment of personal rules may be a precondition for the use of some therapeutic procedures when these procedures violate certain personal rules.

\section{THE DEVELOPMENT OF RULES}

In general, the development of rules and traditions may be due in part to decisions made by closely knit societies which have decided that certain values need to be protected through the use of rules or traditions. However, there are rules and traditions that govern human behavior which are not necessarily derived at the societal level, but are derived from individuals and families as they seek to promote a sense of perceived order and safety in their daily lives. These rules and traditions may be helpful or maladaptive for the family or the individual, depending upon their relevance for their present circum- 
stances. They may be stated either as conditional warnings or as simple imperatives.

Zettle and Hayes (1982) have suggested two reasons for the development and formulation of personal rules. One reason is that the individual may act effectively in the absence of appropriate contingencies from the immediate environment, which usually shape and direct behavior. Another reason is that individuals are reinforced to follow certain rules and traditions by their family and social history, which may be to their advantage or disadvantage.

\section{Rules and the Developmental Process}

Sometimes personal rules are associated with the developmental process and are formed at an early age. Adler (1958) stated that some children who are abused, handicapped, or traumatized by others frequently make a rule, or accept a rule from others, about their future. The rule may be a variation of the following: "My handicap means I will always be a failure on a job;" or, "Since I was abused, I will trust no one." Because of these adverse conditions, the child becomes discouraged and feels that he/she cannot solve the tasks of life, such as work, friendship, and love. The problem with these types of rules is that they may reflect a faulty judgment about the future because the evidence for this judgment is incomplete or lacking. The younger child has only a limited ablity to evaluate the rules it receives from the environment. Therefore, these rules may never be reevaluated or even recognized as the child grows up, and they become guiding principles for the entire life of the child. If a basic maladaptive belief or attitude is fixed at an early age, such as superiority or inferiority, it may become the basis for what Adler (Ansbacher \& Ansbacher, 1956) calls a "private map," which contains rules and directions for behavior based upon this faulty, early self-evaluation. These types of rules may account for such problems as chronic underachievement, isolate behavior, and pervasive feelings of inferiority, which persist over long periods of time due to the fact that they protect the individual from the feared inferiority or prevent the actual testing of the feeling of superiority in daily life. These rules are extraordinarily persistent and difficult to change because they may never have been examined, and the resulting behavior is habitual. Alternatively, the persistence of the rules may be due to the fact that they have been identified and reinforced for years. The response of the environment to this maladaptive 
life style, which is generated by the rule, may tend to confirm the "truth" of the rule.

Piaget (1948) also stated that children are especially vulnerable to the judgments of others. According to him, there is a tendency for younger children to absolutely apply rules to themselves out of deference to authority. These rules relate to social conduct, obedience to parents, use of objects, and methods of restitution and punishment for disobedience. Older children usually apply rules more selectively. This is a result of a reciprocal decision making process between themselves and meaningful people in the environment. Rules may be adapted and changed, to the child's benefit through social compromise, but there is no guarantee of this.

\section{SPECIFIC EXAMPLES}

\section{Rules and Emotional Disorders}

Personal rules may be related to emotional disorders and directly reflect the characteristics of these disorders. Phobics may develop rules related to their experience of anxiety, such as: "Don't go outside without a companion;" or, "Don't ride elevators." These phobic rules are probably derived from the effects of successful avoidance behavior which has brought relief to the phobic individual. Thus, the rule has become the antecedent for further avoidance behavior. The anxious client may be fully aware of the purpose and the actual function of these rules, or the rules may be tacit assumptions which are not completely understood or conscious yet influence behavior (Polanyi, 1964).

The depressed person may follow the rule: "Don't get involved with people, nothing good will come of it;" or, "I never accept compliments, because if people knew how inferior and stupid I am, they would never say them."

In the case of depression, an interactive process between rule development and affect is quite apparent. Beck (1976) has stated that the depressive cognitive organization (schema) may become so severe that there is no logical connection between actual situations and negative interpretations of these situations. In these situations the patient may develop rules about both present and future experiences which are based upon these negative interpretations (schemas) and not in accord with reality.

Patients with obsessive-compulsive disorders provide examples of rule-governed behavior which is rigid and maladaptive. Such patients are truly rule-bound. A patient may fear contamination by dirt or 
germs, and develop a rule which prescribes washing for hours during the day. Such a rule is perceived as inflexible, and, if not obeyed, may result in dire consequences to the individual. In this case the performance of the ritual behavior in response to the rule is often reinforcing and anxiety reducing (Rachman 1976). Thus, the natural and negative consequences of the compulsions, which in the case of excessive washing might be physical pain or social criticism, may be ineffective in bringing into question the value of the rule. Thus, the control of the rule continues unabated and is reinforced by the ritual.

\section{Child Management Strategies}

Personal rules or traditions may also be the foundation for various child management strategies thought to be in the best interest of the child. Yet these strategies may have persistent negative consequences. For example, some parents may passionately believe the following rules: "Spare the rod, and you will spoil the child;" or, "Children must be seen and not heard;" or, "When my child misbehaves, whipping is the best solution." Yet the consequences of following these rules may result in unhappiness for both the child and the parents. However, in actual practice, the adequacy of the rules may not be challenged. Parents are often simply puzzled as to why the rules don't work or they blame the child for noncompliance. Parents may generate these rules as direct response to a contemporary solution or, as is more often the case, they are received as traditions which are thought to be eternally valid.

\section{Role Behavior and Rules}

Gender role behavior is often stated in the form of a rule. For example: "A woman's place is in the home;" or, "A man's home is his castle." These rules are often stated in fragmentary manner as if the details were self-evident. These rules are often expressed in a kind of verbal "shorthand", as evident in the following case excerpt:

John and Many had agreed to develop mutual positive exchanges to increase greater marital satisfaction as a part of their participation in behavioral marital therapy. John had agreed to provide care for the children in the evenings and to prepare them for bed in exchange for Mary's agreement to take care of the family's finances and the payment of bills. Both seemed satisfied with this arrangement until John began to receive criticism from his brother and other relatives. His brother said to him on a number of occasions, "You had better not do too much of this child care business, Mary will 
get used to it, and you know it's really her job not yours." John's response was, "You're right, I'd almost forgotten about that!" John told the therapist that he just couldn't go through with the agreement because it was against his family's traditions.

It was evident that John had almost forgotten the rule, but, when reminded of it, the rule was perceived as inviolate, as if it contained specific provisions for this situation. However, in some instances, individuals may be completely unaware of the rule's existence, yet their behavior appears to be rule-governed since it is repetitive and relatively unaffected by its consequences.

\section{Rules and Work}

Work behavior is often the subject of various rules. A person may accept the rule: "I don't get too close to bosses, it's too dangerous;" or, "I don't ask for help on any job, they will think I am incompetent." These rules will probably be followed in spite of the fact that the present boss may actually desire a close relationship and welcome requests for help. If this is the case, this type of rule-governed behavior illustrates the fact that rules may be followed despite evidence to the contrary or despite changes in circumstances. A practical consequence of work rules is that the social support from supervisors or co-workers, which might moderate such problems as work stress and burnout, is ignored.

\section{Rules and Interpersonal Relationships}

There are many rules which govern relationships with neighbors, friends, or strangers. For example: "Don't trust your neighbors"; or, "Don't date someone from a different religious background;" or, "Never talk to strangers." In these instances there is often no attempt to discriminate differences between people. People in similar categories are perceived as identical and then treated in the same fashion. This lack of discrimination may be a result of how the rule was developed and transmitted from one generation to another. If grandparents experienced problems with their neighbors, it might have been appropriate not to trust them and thus to generate a rule about that situation. But in the transmission of that rule to succeeding generations the original purpose of the rule was forgotten. Succeeding generations of children were taught the rule as a prescription for relations with all neighbors, both trustworthy and untrustworthy, and probably reinforced for accepting it as an unalterable truth. 


\section{Marital Relationships}

The relationship of couples is often under under the control of various rules, such as: "I don't tell my spouse what I really feel, he/she should know that;" or, "I never openly disagree with my spouse, it would destroy the relationship." Such rules may be generated by individuals in an ad hoc manner or transmitted by families. These rules, usually based upon beliefs, have been described by Ellis (1977) and Epstein (1986).

\section{Rules and Health}

There are also rules about physical health, such as: "Don't stop smoking, it will cause you to gain weight;" or, "Only thin people are attractive, therefore I must continue to lose weight;" or, "I always have three drinks before I go to a party, just to relax." These types of rules may contribute to substance abuse and to self-regulatory problems in eating disorders.

\section{Ethnic Rules}

Cultural or ethnic rules may also exert a great deal of control over the behavior of individuals. Some families may subscribe to such rules as: "As a father I make all the decisions in my family;" or, "Children must always respect the authority of their parents." These rules may be part of a family tradition and difficult to change because they are perceived as central to the particular cultural tradition or ethnic character. If they are not identified and addressed, they may hinder or simply disqualify therapeutic strategies designed to improve family relations.

\section{Social Conduct}

There are also rules of social conduct, such as: "Don't call attention to yourself;" or, "I don't ever refuse to help a friend." If these rules are not followed they may result in social disapproval even though they may be maladaptive to the individual. Lange and Jakubowski (1976) have recognized the importance of these rules and suggest that they be discussed and examined as to their usefulness prior to the use of assertive training procedures. 
While the types of rules mentioned above are only suggestive of the wide variety of possible rules, they serve to suggest the pervasiveness of rule application and control in human behavior.

\section{THERAPEUTIC RULES}

Therapists themselves prescribe rules for their patients to foster the development and maintenance of mental health and interpersonal relationships. Hauck (1986) has suggested three rules for achieving marital compatibility, as follows: (1) If your partner does something good to you, do something good in return; (2) If your partner does something bad to you, do something good in return, at least for a reasonable time; (3) If your partner does something bad to you, and talking doesn't help, do something bad in return without anger, guilt, or pity. He states that these rules will assist in bringing a relationship into a fair balance by rewarding appropriate behavior and by not tolerating abuse.

Meichenbaum and Asarnow (1979) have suggested cognitive rules for the self-regulation of behavior and for the therapeutic improvement of academic functioning among children. He contends that many children perform inadequately because they lack appropriate verbal mediators to control nonverbal behaviors. Therefore the trainer's task is to improve self control and task performance by teaching the child a set of verbal rules, usually a set of self-instructions, to recite prior to or during an attempt to gain self-control or an attempt to complete a specific task.

Thomas (1977) has suggested a number of rules for successful marital interactions. He presented three general rules designed to remedy defects in marital communication: (1) Avoid stressful times for positive communication; (2) Don't mix marital decision making with noncontroversial verbal exchange; (3) Structure explicit times for noncontroversial marital communication. Specific rules are also given to promote positive communication through improved verbal specificity and reinforcement. These rules are individualized for each couple, related specifically to each partner's particular communication problems.

While general therapeutic rules may be adaptive for certain clients, a therapeutic rule usually needs to contain methods for adapting it to fit the particular, and many times idiosyncratic, needs of the individual patient, as Thomas has demonstrated. 


\section{THE BENEFITS OF RULES}

Wessler (Cited in Gilmore, 1986) makes the interesting distinction between functional and dysfunctional rules of living by saying that a functional rule leads to a whole variety of human emotions including joy, sadness, pleasure, regret, frustration, annoyance, and love. A dysfunctional rule leads to other emotions including guilt, shame, depression, and pride. While this distinction was made in the context of fostering the idea of a qualitative as opposed to a quantitative distinction between irrational and rational beleifs, this classification model for rules may not always be valid when one is speaking of rule-governed behavior. While there may be irrational aspects of rules and their consequences, all rules are not necessarily completely functional or dysfunctional. It is not always necessary to discard a maladaptive rule, but rather to change it and improve its clarity and its timeliness in response to environmental consequences. This is especially important if the client wishes to maintain a certain value inherent in the rule. If this is done, the consequence of following a particular rule may not always be dysfunctional.

In addition, it is important to recognize that some personal rules or family traditions may have some helpful and positive aspects even though initially dysfunctional. There is a tendency for clients to discard all rules from the past if they discover some defects in them and to make up new ones in an impulsive fashion. For example, an individual may decide to marry someone from a different cultural or religious background, in spite of a parental rule to the contrary. Because of parental disapproval, the individual refuses to follow any rules or traditions of the family, some of which may be helpful.

\section{THE ASSESSMENT OF RULES}

Beck and Emery (1985) have stated that rules need to be evaluated and assessed by collaborative empiricism in which the patient and the therapist work together to reformulate them according to the reality of the client's world.

Skinner (1969) has provided a set of guidelines for the assessment of rules which takes into account the special operant characteristics of rules and which I believe can be blended into the cognitive therapy approaches to the rule change process. He has stated that individuals may perceive rules as discriminative stimuli for behavioral responses. Such rules may be defined as memory traces composed of information 
containing descriptions of antecedents, which function as anticipatory guidelines regarding how to behave in certain situations. Rules also contain description of the behavior required in certain situations and descriptions of the probable consequences of rule compliance. A rule is then an expressed contingency, a description of behavior in a certain setting and its probable result, a description of an if-then relationship. According to Skinner, behavior is rule-governed when the rule can be stated by the individual and when the rule actually guides behavior.

Skinner (1969) also states a number of ways that a rule might be defective. First, a defective rule does not specify the exact situation in which the rule should be applied. Second, a defective rule does not present a specific description of the behavior required. Third, a defective rule does not provide a method of adapting the rule to changing environmental conditions. Sometimes rules may be defective or ambiguous simply because they lack any of these three elements. This fragmentation of rules may be one of the reasons for the lack of personal awareness of some rules. If parents use the rule, "Spare the rod and spoil the child," as the basis for a child management strategy, it may be defective for this purpose because of its ambiguity. It is ambiguous because: (a) It does not describe the actual situation in which the rod needs to be used; (b) It does not describe what you do when you use the rod or even what the rod is; (c) It presumes that if you use the rod, you will avoid spoiling the child; (d) There is no mechanism for possible adaptation of the rule if it doesn't work with a particular child, or if the negative effects of punishment are maladaptive for the child. One possible redeeming feature of the rule is that it presents a value, namely to avoid spoiling the child, but that value could be maintained by a more adaptive rule.

A less ambiguous set of rules for dealing with child misbehavior has been suggested by Miller (1975). In summary, he states four specific procedural rules for parents to use when giving negative feedback to their children about a behavioral problem: (a) Obtain the child's attention; (b) State the problem briefly, simply, and unambiguously; (c) State your feelings about the behavior and its interpersonal consequences; (d) Suggest alternative behaviors, and reinforce the chosen alternative. This set of rules describes the situation for their use, the consequences of rule compliance, the behaviors necessary to implement the rule, and is flexible about the generation of alternative behaviors for reinforcement. While there is no perfect rule, this set of rules does meet the necessary requirements.

It is also important to understand that a rule cannot contain all the 
elements of a skill, nor can skills be completely represented by rules. The skills necessary for the implementation of rules need to be developed through role play procedures and behavioral rehearsal.

\section{THE CHANGING OF RULES}

Beck and Emery (1985) stated that a rule's alteration should be made by an analysis of faulty logic in the rule, by hypothesis testing to assist in discovering the presence of the rule, by generating alternative interpretations of the problematic situation, and by the developing of coping plans and alternative behavior through role play and behavioral rehearsal. There may be a number of difficulties in such rule alteration because the force of habit, and the implicit character of many rules, make rule identification possible only by a process of the assessment of individual cognition and related behavior. To assist in this process of self-evaluation, the concept of key words, such as "musts" and "shoulds" formulated by RET, may be of assistance. The therapeutic pursuit of the rule related concepts that have generated the "musts" and "shoulds" of life may assist the individual in identifying the implicit rules which guide their behavior, especially if these rules have been developed in the remote past and never quite fully understood.

Skinner (1969) adds an important concept to this rule modification process, namely that a maladaptive rule does not necessarily need to be discarded and a new one substituted, but can be made more flexible to account for the ever changing contingencies in the environment. A reformulated or good rule should have a specific situation in which it can be applied. It should offer an exact description of the type of behavior which is prescribed. It should suggest expected consequences which probably will occur. If these consequences do not occur, it should be understood that the rule can be changed to adapt to the changing consequences in the environment. In this way rule-governed behavior becomes contingency-shaped behavior

\section{THE ISSUE OF AWARENESS}

The issue of awareness related to rule assessment and modification is a difficult one. It is evident that patients are not always immediately aware of the rules that guide their behavior, but describe 
such rules clearly only after time for reflection. On the other hand, it is tempting, in the clinical situation, to suggest to the patient that he/she holds a rule, even though the patient is not aware of it, and to suggest its content without adequate information.

Meichenbaum and Gilmore (1984) have stated that maladaptive cognitive processes that are habitual, automatic, or unrecognized need to become conscious for the successful interruption of a chain of maladaptive events. In cases where the existence of a rule is not certain, a number of tactics can be used. The therapist can encourage the patient to to consider repetitive behaviors, which are done in a variety of situations, to see if an implicit rule would explain their consistency. Specific questions may also assist in the development of rule awareness. One might ask the patient to describe a hypothetical situation in which a rule might guide behavior in order to sensitize the individual to the nature and function of rules. Another tactic might be to ask the patient to describe a rule-governed behavior which does exist in his/ her life, and to compare this example to the problem in which a maladaptive rule is suspected. The patient may also be asked as to the type of rule which might relate to a problem area. It is also important to inquire about the relationship between the intentions and outcomes of behaviors. Discrepancies between these two factors may suggest the presence of an implicit rule, which persists in its influence in spite of negative consequences.

Skinner (1969) discounts the value of mental events (private experiences) as useful in the experimental analysis and modification of behavior. However, his insistence upon the verbal report of rules, complete or incomplete, and their modification in relation to external environmental contingencies allows the rule to become overt and subject to public scrutiny and change. Yet, the awareness of rules, and resulting objectivity through verbal report, are only the first steps. The rule must be changed and adapted to present environmental contingencies, and the behaviors developed to implement the intent of the rule, through shaping, modeling, and reinforcement from the environment. Thus, behavior governed by precursors of rules or maladaptive rules becomes fully rational behavior governed by explicit, complete, and accurate rules. These types of rules then constitute rational knowledge.

\section{CONCLUSION}

This particular conception of rule development, assessment, and change based on cognitive and operant perspectives can be useful for 
the cognitive therapy of maladaptive rules. I find this approach useful because it basically relies upon both cognitive and environmental sources as they function as determinants of rule development, maintenance, and revision. This dual approach also provides a measure of specificity as to how this interaction occurs, and its relevance for assessment and intervention. While it is true that there are many causes or antecedents of behavior other than rules, it is my clinical impression that rule-making activities and the effects of traditional rules, are significant causes of emotional distress and maladaptive behavior. Further research is needed to monitor the effects of rule change on emotions and behavior and to assess the pervasiveness and nature of rule-governed behavior in both clinical and nonclinical samples.

\section{REFERENCES}

Adler, A. (1958). What life should mean to you. New York: Capricorn Books.

Ansbacher, H. L. \& Ansbacher, R. R. (Eds.). (1956). The individual psychology of Alfred Adler. New York: Basic Books.

Beck, A. (1976). Cognitive therapy and the emotional disorders. New York: International Universities Press.

Beck, A. T., \& Emery, G. (1985). Anxiety disorders and phobias. New York: Basic Books.

Ellis, A. (1977). The nature of disturbed marital interactions. In A. Ellis \& R. Grieger, Handbook of rational-emotive therapy (pp. 170-176). New York: Springer.

Epstein, N. (1986). Cognitive marital therapy: Multi-level assessment and intervention. Journal of Rational-Emotive Therapy, 4, 68-81.

Gilmore, I. (1986). An exposition and development of the debate on the nature of the distinction between appropriate and inappropriate beliefs in rational-emotive therapy. Journal of Rational-Emotive Therapy, 4, 155168.

Hauck, P. A. (1986). Innovations in marriage counselling. Journal of Rational-Emotive Therapy, 4, 38-49.

Lange, A. J., \& Jakubowski, P. (1976). Responsible assertive behavior. Champaign, IL: Research Press.

Meichenbaum, D., \& Asarnow, J (1979). Cognitive-behavioral modification and metacognitive development: Implications for the classroom. In P. C. Kendall \& S. D. Hollon, (Eds.), Cognitive-behavioral interventions (pp. 11-35). New York: Academic Press.

Meichenbaum, D. \& Gilmore, J. B. (1984). The nature of unconscious processes: A cognitive-behavioral perspective. In K. S. Bowers \& D. Meichenbaum (Eds.), The unconscious reconsidered (pp. 273-298). New York: John Wiley.

Miller, W. H. (1975). Systematic parent training. Champaign, IL: Research Press. 
Piaget, J. (1948). The moral judgment of the child. Glencoe, IL: Free Press.

Polanyi, M. (1964). Science, faith and society. Chicago: University of Chicago Press.

Rachman, S. (1976). The modification of obsessions: A new formulation. Behaviour Research and Therapy, 14, 437-443.

Skinner, B. F. (1969). Contingencies of reinforcement. New York: AppletonCentury-Crofts.

Thomas E. J. (1977). Marital communication and decision-making. New York: Free Press.

Zettle, R. D., \& Hayes, S. (1982). Rule-governed behavior: A potential framework for cognitive-behavioral therapy. In P. C. Kendall (Ed.), Advances in cognitive-behavior research and therapy (Vol. 1, pp. 73-118). New York: Academic Press. 